\title{
Splice Site SNP
}

National Cancer Institute

\section{Source}

National Cancer Institute. Splice Site SNP. NCI Thesaurus. Code C45574.

An inherited single base substitution in a sequence of eukaryotic DNA located in either an acceptor (3' or downstream) or donor (5' or upstream) splice site of a gene. Functional single nucleotide polymorphisms in these intron-exon junctions can cause incorrect RNA splicing which, in turn, alters gene expression. 